\title{
Assessing the correlations between subjective symptom scores and turbinoseptal relationships in pretreatment adults with chronic rhinosinusitis
}

\author{
Adekunle Adeyemo ${ }^{a}$, Sanyaolu A. Ameye ${ }^{a}$, Yemisi B. Amusa ${ }^{a}$, \\ Ajibola T. Osukoya ${ }^{b}$, Akumbu S. Ohuche ${ }^{b}$
}

${ }^{a}$ ENT Surgery Unit, Department of Surgery, Obafemi Awolowo University, ${ }^{b}$ ENT Surgery Department, Obafemi Awolowo University Teaching Hospital, Ile, Nigeria

Correspondence to Adekunle Adeyemo, MBBS, FWACS, ENT Surgery Unit, Department of Surgery, Obafemi Awolowo University, Ile, Nigeria. Tel: +234 8903670 1170;

e-mail:kunleard@gmail.com

resented-atPart of this work was presented previously at the Pan African Federation of Otorhinolaryngology Conference 2017. 14

November 2017, Abuja

Received 5 April 2018

Accepted 1 August 2018

The Egyptian Journal of Otolaryngology 2018, 34:248-252 Background
This study was undertaken to assess the correlations between subjective symptom
score in patients with chronic rhinosinusitis and endoscopic turbinoseptal relationship (TSR).

Aim

To assess the pattern of TSR and their correlations with symptom score in patients with chronic rhinosinusitis.

Settings and design

This was an observational study in a tertiary/teaching hospital setting

Patients and methods

Consecutive pretreatment adults with chronic rhinosinusitis completed the sinonasal outcome test 22 (SNOT22) and had nasal endoscopy. At endoscopy, the TSR was determined, as well as the presence of nasal polyps.

Statistical analysis

Mean SNOT22 score was calculated and TSR types were grouped and their distribution documented with types 3 and 4 taken as unfavorable types. $\chi^{2}$-Tests were used to determine the correlations between turbinoseptal types, presence of nasal polys, and SNOT22 scores with the level of significance set at $P$ value up to 0.05 .

\section{Results}

A total of 53 [23 (43.4\%) men and $30(56.6 \%)$ women] patients with a mean age of $42.5 \pm 18.6$, completed the study. Median symptom duration was 36 weeks (13-112 weeks). Mean SNOT22 score was 29.7 \pm 2.8 . Unfavorable TSR types were found in $42.5 \%$ of nostrils, more on the right $\left(\chi^{2}=13.2 ; P \leq 0.01\right)$.

There is no significant correlation between the presence of unfavorable TSR and worsening total SNOT22 scores [R $(\mathrm{K}-\mathrm{S}=0.13 P=0.95) \mathrm{L}(\mathrm{K}-\mathrm{S}=0.34, P=0.07)]$.

\section{Conclusion}

Unfavorable TSR is common in patients with chronic rhinosinusitis. However, there is no correlation between the presence of abnormal TSR and symptom scores.

\section{Keywords:}

chronic rhinosinusitis, septum, sinonasal outcome test 22 , turbinate

Egypt J Otolaryngol 34:248-252

(C) 2018 The Egyptian Journal of Otolaryngology

$1012-5574$

\section{Introduction}

Anatomic variations of the lateral nasal wall and the nasal septum have been identified as known risk factors for the development of rhinosinusitis [1,2]. These anatomic variations predispose to disruption of the normal mucociliary functions of the sinuses setting up a cascade of events that ultimately result in chronic rhinosinusitis. In spite of these, the contribution of these variations to the symptomatology of rhinosinusitis has been controversial as these variations have been described in normal people [3].

Various classification methods for chronic rhinosinusitis have been developed in recognition of the heterogeneous nature of this disease $[4,5]$. Schaitkin et al. [4] classified chronic rhinosinusitis based on the presence of anatomic variations, suppuration, polyps, and hyperplastic diseases. They attempted to relate these classifications with the success of endoscopic sinus surgery.

Sinonasal outcome score 20 [6] and its derivatives are the commonly used instruments for assessing subjective symptom severity in patients with chronic rhinosinusitis. Previous attempts at correlating objective scores such as endoscopic scores and subjective assessment of severity such as symptom

This is an open access journal, and articles are distributed under the terms of the Creative Commons Attribution-NonCommercial-ShareAlike 4.0 License, which allows others to remix, tweak, and build upon the work non-commercially, as long as appropriate credit is given and the new creations are licensed under the identical terms. 
scores have yielded inconsistent results [7-9]. Most of these endoscopic scoring systems did not incorporate assessment of the nasal septum or its relationship with the middle turbinate into the scoring system.

This study is aimed at documenting the pattern of turbinoseptal relationship (TSR) and its relationship to the symptomatology of chronic rhinosinusitis using sinonasal outcome score 22 (SNOT22) [10].

\section{Patients and methods}

This was an observational study of consecutive pretreatment adult patients diagnosed with chronic rhinosinusitis in the ENT clinic of our hospital between May 2016 and June 2017. Ethical approval was obtained from our institutional research and ethics committee before start of the study. Excluded from the study are patients with a previous history of facial trauma, sinonasal tumors, nasal surgeries, and patients with known drug allergies to any of the agents used in nasal endoscopy. Written informed consent was obtained from all participants.

SNOT22 [10] was administered to each consenting participant. Thereafter, the patients were subjected to diagnostic nasal endoscopy using Hopkins $30^{\circ}$ telescopes after topical nasal preparation with topical anesthetic agent (2\% lignocaine) and decongestant (adrenaline 1 : 10 000). At diagnostic nasal endoscopy, the TSR was determined for each nostril based on the classification system of Schaitkin et al. [4].

The information obtained included demographic details of participants, duration of symptoms, SNOT22 [10] score and the TSR for each nostril. The presence of type 1 or type 2 (Figs 1 and 2) TSR was taken as favorable, while types 3 (Fig. 3) and 4 (complete inability to visualize the middle turbinate resulting from lateral deviation of the septum coming in contact with lateral nasal wall) were taken as unfavorable TSR.

The results are summarized in charts and tables as appropriate; the association between TSR and SNOT22 score were tested statistically with the level of statistical significance set at $P$ value up to 0.05 .

\section{Results}

A total of 53 patients with a mean age of $42.5 \pm 18.6$, constituting 23 (43.4\%) men and 30 (56.6\%) women completed the study. The patients have had their symptoms for between 13 and 112 weeks prior to presentation (median 36 weeks).
Figure 1

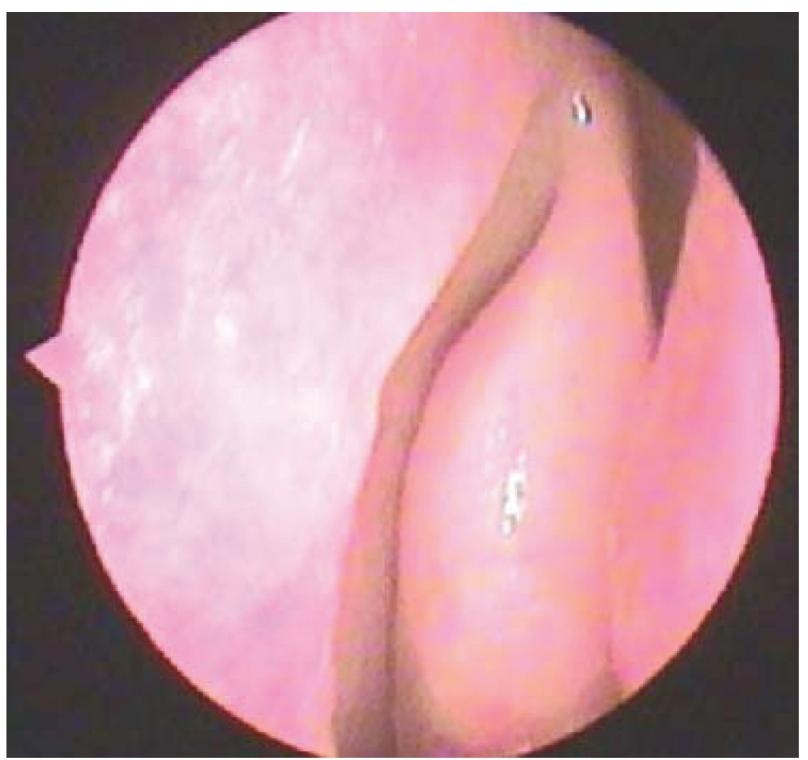

Type 1 TSR: note the vissible medial and lateral attachments of the middle turbinate.

Figure 2

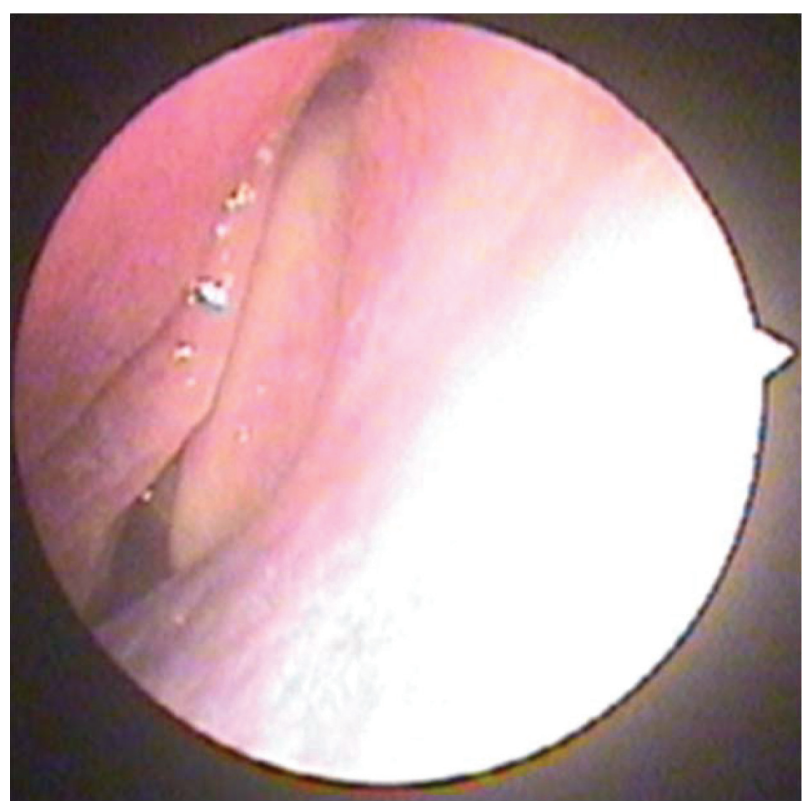

Type 2 TSR: note the partial obscuring of the medial attachment of the middle turbinate by the septum.

The mean SNOT22 score was $29.7 \pm 2.8$ among the participants. Figure 4 shows the five most bothersome symptoms on the SNOT22 score with nasal obstruction being the most common.

Unfavorable TSR types were found in $42.5 \%$ of nostrils, significantly more common on the right $\left(\chi^{2}=13.2 ; P \leq 0.01\right)$. 


\section{Figure 3}

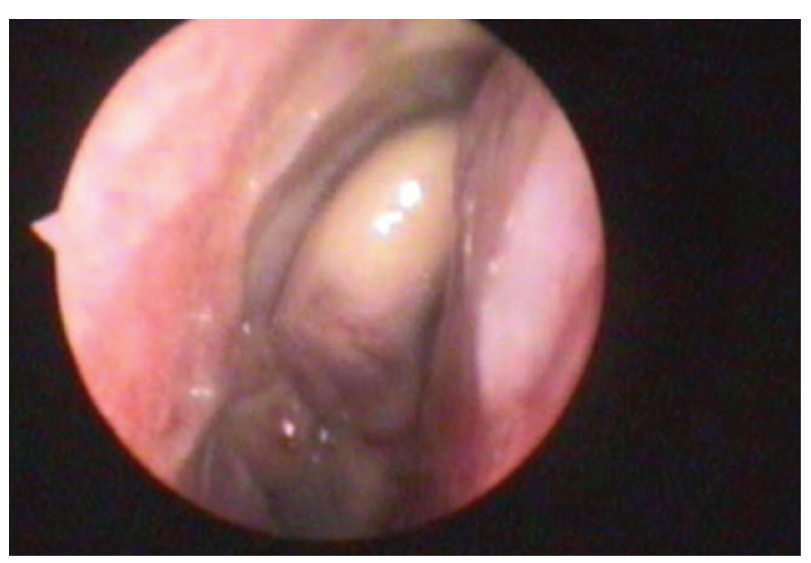

Type 3 TSR: note the complete obscuring of the attachments of the middle turbinate leaving only the turbinate head vissible.

There is no significant correlation between the presence of abnormal TSR and worsening total SNOT22 scores $[\mathrm{R}(\mathrm{K}-\mathrm{S}=0.13, \quad P=0.95) \mathrm{L}(\mathrm{K}-$ $\mathrm{S}=0.34, P=0.07)]$.

Nasal polyps were found in five $(9.4 \%)$ patients. The presence of nasal polyp was not found to have any significant relationship with presence of unfavorable TSR $(P=0.40$ and 1.0 , for right and left nostrils, respectively). Figure 5 shows the distribution of TSR among the patients.

\section{Discussion}

This study fails to demonstrate a significant relationship between unfavorable TSR and symptom scores in patients with chronic rhinosinusitis. In spite of the foregoing, the presence of unfavorable TSR in up to $40 \%$ of our patients points to the fact that the patients require surgery for their rhinosinusitis, up to $40 \%$ of them will require septal surgery in addition to their sinus surgery to gain access to their middle meatus. Conversely, the absence of a significant relationship suggests that isolated septal surgery is unlikely to benefit the patients with abnormal TSR.

Previous studies aimed at determining the role of septal deviation in the symptomatology of rhinosinusitis have yielded inconsistent results. Our study is in contrast to that of Calhoun et al. [11] who demonstrated a significant correlation between severity of septal deviation and patient symptoms. Calhoun et al. [11] however assessed septal deviation using computed tomography scan, in contrast to our study where endoscopic assessment was done. The prevalence of septal deviations has been documented to vary between $13 \%$ [4] and 79\% [5], depending on the method of diagnosis and definition with majority of such deviations being asymptomatic. This absence of correlation with symptom scores may be a consequence of the heterogeneous nature of chronic rhinosinusitis with recognized multiple etiologies which may coexist in the same individual. The prevalence of nasal polyps was high in this study which may indicate the impact of racial variations in the prevalence of nasal polyps as studies in other racial groups have reported a lower incidence of nasal polyps [12]. Nasal polyps are essentially oedematous prolapsed sinonasal mucosa, generally associated with the presence of sinonasal inflammation, although the actual pathophysiological steps involved are still controversial. The absence of correlation between unfavorable turbinoseptal variations and the presence of nasal polyps suggests that turbinoseptal anatomic relationship did not contribute to the presence of sinus inflammation in patients with chronic rhinosinusitis.

Endonasal anatomic variations have been studied in health and disease with several documentations of such variations in otherwise normal people. In spite of these, however, it is accepted that such variation can make surgery precarious or difficult which underscores the need for a preoperative knowledge of the precise endonasal anatomy of individuals for proper surgical planning and safety.

The SNOT22 is a popular instrument for determining the quality of life of patients with sinonasal disorders [13]. This instrument measures five distinct domains of quality of life of patients. These domains include rhinologic symptoms, extra-nasal rhinologic symptoms, ear/facial symptoms, psychological dysfunction, and sleep [14]. Studies have shown that patients with higher aggregate scores have more severe disease. There are also evidences that rhinologic symptoms are more likely to be controlled by treatment. Our study shows that the most bothersome complaints of our patients are essentially physical complaints with psychological and sleeprelated impairment rating loss. Although studies have established that patients domain-specific impairment impact on the choice of treatment [15]. The role this played in our patients cannot be determined as our study did not set out to determine factors that motivate patients to seek treatment. Previous studies have shown improvement in SNOT22 scores in patients receiving treatment for chronic rhinosinusitis. These studies also show a greater degree of improvement in patients undergoing surgery compared with patient undergoing medical management [16]. Our study however did not detect a significant correlation 


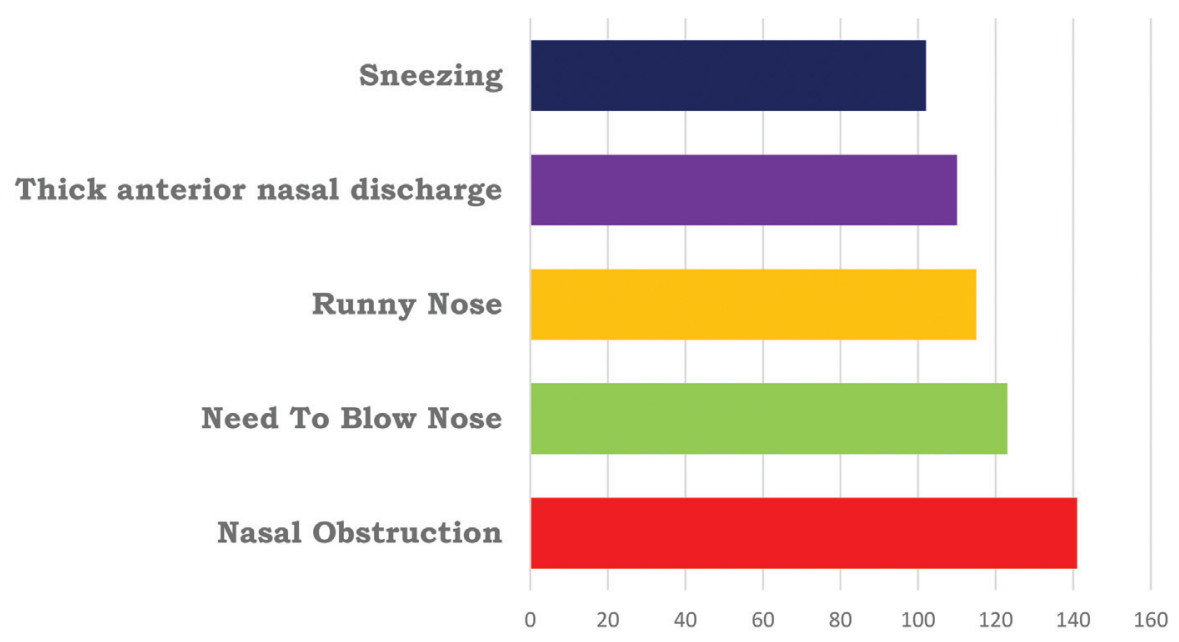

Five Highest ranked syptoms on SNOT22 among participants.

Figure 5

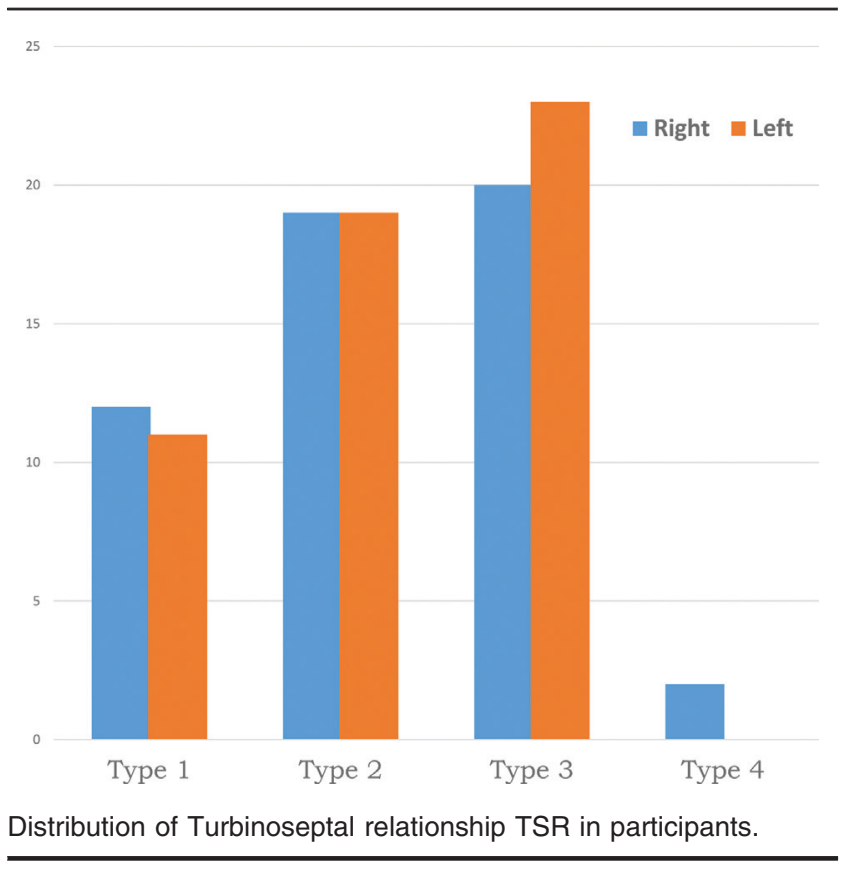

between SNOT22 scores and anatomic variations involving the nasal septum and the presence of nasal polyps. These findings suggest that our patients may benefit from medical management with surgery reserved only for medical failures. On the basis of our findings, we suggest that septal surgery as a sole treatment modality should be avoided as this is unlikely to result in a meaningful improvement in patient symptomatology. In spite of the foregoing, we should be mindful of the challenges that will arise from poor visualization of the middle meatus in patients with unfavorable TSR. This poor visualization can increase the risk of surgery and increase the complication rates or even impact on the completeness of surgery. We therefore advocate that patient with unfavorable TSR undergoing sinus surgery should have an initial septoplasty for the purpose of improved surgical access and visibility.

Our studies suffers from the limitations common to all cross-sectional studies; therefore, all references to the potential impact of septal surgery on symptom resolution while suggested by our studies cannot be conclusive, based on our study design. Therefore, there is a need for further studies utilizing different designs to determine the exact impact of septal surgeries on patient with chronic rhinosinusitis.

In spite of the limitations of this study, we conclude by stating that practitioners intending to treat chronic rhinosinusitis surgically should be aware of the possibility of encountering patients with unfavorable TSR and should therefore be prepared to perform an adjunct septoplasty in such patients.

\section{Financial support and sponsorship}

Nil.

\section{Conflicts of interest}

There are no conflicts of interest.

\section{References}

1 Lanza DC, Kennedy DW. Adult rhinosinusitis defined. Otolaryngol Head Neck Surg 1997; 117:S1-S7.

2 Meltzer EO, Hamilos DL, Hadley JA, Lanza DC, Marple BF, Nicklas RA, et al. Rhinosinusitis: establishing definitions for clinical research and patient care. J Allergy Clin Immunol 2004; 114:155-212.

3 Baraniuk JN, Maibach H. Pathophysiological classification of chronic rhinosinusitis. Respir Res 2005; 6:149.

4 Schaitkin B, May M, Shapiro A, Fucci M, Mester SJ. Endoscopic sinus surgery: 4-year follow-up on the first 100 patients. Laryngoscope 1993; 103:1117-1120. 
5 Earwaker J. Anatomic variants in sinonasal CT. Radiographics 1993; 13:381-415.

6 Piccirillo JF, Merritt Jr MG, Richards ML. Psychometric and clinimetric validity of the 20-item sino-nasal outcome test (SNOT-20). Otolaryngol Head Neck Surg 2002; 126:41-47.

7 Pokharel M, Karki S, Shrestha B, Shrestha I, Amatya R. Correlations between symptoms, nasal endoscopy computed tomography and surgical findings in patients with chronic rhinosinusitis. Kathmandu Univ Med J 2015; 11:201-205.

8 Bist SS, Varshney S, Bhagat S, Mishra S, Agrawal V, Kabdwal N. Study of the anatomical variations in the middle meatus on nasal endoscopy. Clin Rhinol Int J 2013; 6:16-21.

9 Chen H, Katz PP, Shiboski S, Blanc PD. Evaluating change in healthrelated quality of life in adult rhinitis: responsiveness of the Rhinosinusitis Disability Index. Health Qual Life Outcomes 2005; 3:68.

10 Hopkins C, Gillett S, Slack R, Lund V, Browne J. Psychometric validity of the 22-item sinonasal outcome test. Clin Otolaryngol 2009; 34:447-454.
11 Calhoun KH, Waggenspack GA, Simpson CB, Hokanson JA, Bailey BJ. CT evaluation of the paranasal sinuses in symptomatic and asymptomatic populations. Otolaryngol Head Neck Surg 1991; 104:480-483.

12 Deal RT, Kountakis SE. Significance of nasal polyps in chronic rhinosinusitis: symptoms and surgical outcomes. Laryngoscope 2004; 114:1932-1935.

13 Browne JP, Hopkins C, Slack R, Cano SJ. The sino-nasal outcome test (SNOT): can we make it more clinically meaningful? Otolaryngol Head Neck Surg 2007; 136:736-741.

14 Pynnonen MA, Kim HM, Terrell JE. Validation of the sino-nasal outcome test 20 (SNOT-20) domains in nonsurgical patients. Am J Rhinol Allergy 2009; 23:40-45.

15 Soler ZM, Rudmik L, Hwang PH, Mace JC, Schlosser RJ, Smith TL. Patientcentered decision making in the treatment of chronic rhinosinusitis. Laryngoscope 2013; 123:2341-2346.

16 DeConde AS, Mace JC, Alt JA, Soler ZM, Orlandi RR, Smith TL. Investigation of change in cardinal symptoms of chronic rhinosinusitis after surgical or ongoing medical management. Int Forum Allergy Rhinol $2015 ; 5: 36-45$. 